\title{
Erich Meyerhoff, AHIP, FMLA, 1919-2015: a remembrance
}

\author{
Stephen J. Greenberg, MSLS, PhD
}

See end of article for author's affiliation.

DOI: http://dx.doi.org/10.3163/1536-5050.104.4.003

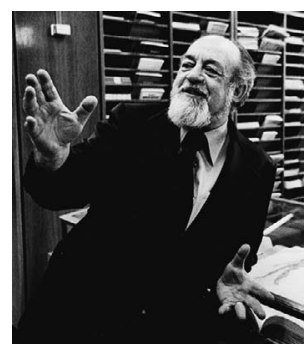

Erich Meyerhoff, AHIP, FMLA - librarian, archivist, and a friend and mentor to generations of colleagues in both fields-died in New York City on December 26, 2015. He was ninety-six years old. There can be few in our field who were so universally respected, loved, and revered as Erich.

He was born in Braunschweig, Lower Saxony, Germany, in 1919, the son of Karl and Irma Meyerhoff. As a Jew of liberal political beliefs, it was clear by 1935 that Germany was a dangerous place, so his parents sent him to New York, where he aggressively pursued an education. He earned his bachelor of science degree from the City College of New York (CCNY), while also helping to get the rest of his family out of Germany. He served in the US Army during the Second World War, where his knowledge of the German language as a native speaker was put to good use. Returning to New York after the war, he earned a master's degree from the New York School of Social Work (now the Columbia University School of Social Work) in 1949. He then went on to what would become his life's focus: working in libraries, and medical libraries in particular.

In February of 1950, Erich began to attend classes at Columbia University's School of Library Service. He graduated in August of the following year. At some point, probably in the summer of 1950, he took Estelle Brodman's legendary course in medical librarianship. Earlier alumni of that course included Louise Darling, Jacqueline Felter, and Frank Bradway Rogers, and some sources maintain that Erich was in the same class as Darling and Rogers, but he always demurred. Archival records at Columbia and the University of California-Los Angeles (UCLA) bear him out: Darling and Rogers took the class in 1949. After graduation, Erich began working at Columbia University's Health Sciences Library, before moving on to Downstate Medical
Center in Brooklyn and State University of New York (SUNY) Buffalo.

In 1970, he was named director of the Medical Library at Cornell University in New York City, a position he would hold until his retirement in 1986 (he was made an assistant dean in 1977). He was also active throughout the profession. He was a Fellow of the American Association for the Advancement of Science, the New York Academy of Medicine, and the Medical Library Association (MLA). His work with MLA was recognized by that group giving him its two most prestigious accolades: the Janet Doe Lectureship in 1977 and the Marcia C. Noyes Award in 1997. Starting in 2017, MLA has renamed its award given to the best unpublished essay in the history of the health sciences to honor him: the Erich Meyerhoff Prize.

Erich was self-effacing to a fault, but if he ever expressed pride in his accomplishments, it was regarding the Medical Library Center of New York (MLCNY). Both an archive of older medical journals and a consortium of libraries, MLCNY was developed to preserve the medical literature, while sparing space for libraries that were fast outgrowing their physical boundaries. Erich served as its founding director, from 1961 to 1967, and later as director emeritus. During his tenure, MLCNY developed the Union Catalog of Medical Periodicals (UCMP), which simplified the interlibrary loan process for participating libraries. When MLCNY closed its doors for the last time in 2003, Erich consented to participate in an oral history (after refusing for many years to be interviewed about his personal career). Though he was "not important," MLCNY was. His oral history and article in the Journal of the Medical Library Association (JMLA) [Death in the family: the Medical Library Center of New York, 1960-2003. 2004 Jan;92(1):4] serve as memorials of this innovative program.

However, this bare recitation of Erich's career does not even begin to measure the influence that he had on his profession and his colleagues. To do that, you must let his colleagues speak about the man they knew. 


\section{Rachael K. Anderson, AHIP, FMLA:}

Erich exuded warmth and was irrepressible in his enthusiasm for ideas and people, especially for medical librarians he thought were doing new and interesting things. Medical libraries interested him even though he was very long past retirement. He continued to attend annual meetings of the Medical Library Association, and just last winter, when we spoke on the phone, he inquired whether I planned to go to the Austin meeting. He retired multiple times. He retired from Cornell and then worked at the library of a Veterans Administration (VA) hospital. When he stopped working there, he volunteered for years to work on the archives at [New York University] NYU.

I met Erich in 1964 when I started to work part-time at the Mount Sinai Hospital and he was founding director of the neighboring Medical Library Center of New York. At the annual MLA meeting in Boston in 1966, I knew no one, and he took me under his wing to meet some more senior members of the profession and go to dinner with groups of them. Erich was passionate about the Medical Library Center [MLC] and the ideas of cooperation and collaboration that underlay it. When it was closed down in 2003, he was extremely distressed. For years he had turned down multiple requests to be interviewed for the MLA oral history program; however, when I suggested that he be interviewed about only MLC, not about his own career, because its story needed be told and preserved, he readily agreed. During that interview, he became so worked up about some of what occurred, he started pounding on the table so hard I feared that part of the conversation would be obscured on the tape we were using to record it. Erich cared, truly cared, about medical librarians, libraries, and their future. He had an abiding interest in them till the end of his life.

He was generous personally. After I moved to Tucson, Arizona, he sent me boxes of chocolate-covered matzohs and chocolate-covered orange peels for my first Passover away from New York, fearing that I no longer had access to such treats out here.

\section{Lucretia W. McClure, AHIP, FMLA:}

Friendship is an endearing gift of membership in MLA. When you go to the meeting for the first time, you may not know anyone. If you are fortunate you will meet someone who becomes a friend. That was my experience with Erich Meyerhoff. I met him at an Upstate New York Chapter meeting in the early 1960s. He welcomed all the new librarians and included them in the discussions and the events. From that time on, we were friends and colleagues.

Erich continued his attendance at national and chapter meetings well into his nineties. I was awed by his knowledge and his willingness to help an individual struggling with a problem. He never turned anyone away and was a constant reminder of the value of our work. Being with him guaranteed a good discussion and a good deal of laughter and joy. His Janet Doe Lecture, "Foundations of Medical Librarianship," is a valuable history of MLA advances and changes through the early days of automation. It is worth reading again and again.

Erich and I have been friends for fifty some years. My last communication from him was the letter he wrote the day before his death. There will be no one like him again.

\section{Mark E. Funk, AHIP, FMLA:}

I knew of Erich long before I met him. For many years, MLA would print an annual report that was part of the registration package at the annual meeting. It contained reports from all the committees, task forces, sections, and chapters. Almost nobody read it. But I remember at practically every business meeting, when the floor was open for questions, Erich would come to the microphone. Perhaps I only imagined the brief look of panic in the association officers' faces who were on the stage. Erich had read through the reports and had serious questions about finances and policies. He was never confrontational but felt that clarity was needed. An officer would then either further explain the situation or promise to find the answer.

Erich never stopped being a librarian. During part of his later years, Erich worked at a VA library in Manhattan. The library couldn't afford to purchase a lot of new materials, so Erich got creative. He came to my office with a shopping list of reference books and directories. He asked if he could get the old editions as my library got the new ones. "Not a problem," I said. "Would you like us to send them to you via the library consortium courier?" "Oh, no, just tell me when they're ready, and I'll come and get them." Even though many of these were big heavy books, Erich would come in with his rolling walker, stack the books on the seat, and head back to his library.

Erich was generous and kind. After I came to Weill Cornell Medical Library in 1987, I heard from others in the city that our library was considered a "mini-United Nations." Erich had only recently retired in 1986, so most of the staff at that time had been hired by him. And indeed, our staff was a rainbow of races and nationalities. Erich liked to give people a chance and practiced this belief as director.

Erich gave a fabulous Janet Doe Lecture in 1977. After I gave mine in 2012, he sent me a note to express his pleasure and admiration for having heard mine. I treasure this note from one of our giants. 


\section{Carolyn Anne Reid, AHIP:}

First words that come to mind when I think of Erich: generous, kind, thoughtful, supportive, professional, energetic, independent, warm, and loving.

I don't remember exactly when I first met Erich in person, but I certainly was aware of him and his commitment to our profession from his very active participation in the association. My first attendance at an annual MLA meeting was in 1971, in New York City, where I met many MLA leaders due to the perseverance of my library school teachers, including Charles W. Sargent, AHIP, FMLA, and Estelle Brodman. They shepherded their five University of Missouri health sciences library school students throughout the intricacies of the meeting schedule, social functions, and [continuing education] CE courses, making sure we met key people. In the following years, I soon recognized Erich since he always stood out at annual meetings, regularly making comments at the sessions especially during the business meetings. In recent years, at MLA meetings, I often had the great pleasure of dining with him or sitting with him during sessions. It's very difficult to imagine MLA without him.

I came to know him much better after moving to NYC in 1987. Although already retired from Cornell University Medical College (CUMC), he continued to receive health care at the medical center and to access the library resources and facilities. After a doctor's visit, he would stop by the library to say hello and chat with the staff, and would always drop by the director's office to talk with Robert Braude, AHIP, FMLA, and me. It was such a pleasure to see him and catch up with his activities. I never ceased to be amazed at his continued high level of involvement in libraries and just life in general, even to the last. His support for Bob as director and encouragement of me as I moved into that position was gratifying and beneficial.

Also significant was his support of the local MLA chapter. No other local medical school library director attended and participated in chapter meetings and functions so regularly as Erich. Even after retirement, he was a regular presence at the annual meeting and spring dinners. As recently as last October, Mark and I sat with him at lunch during the meeting, talking about the changes in biomedical science, information resources, and library management during recent years. It was always a joy to see and talk with him.

In 2001, I became director of the Weill Cornell Medical Library, and Erich sent me congratulations in the form of a supportive note and a peace lily, which I proudly displayed in my office for many years. In 2010, when I left the medical college, Erich attended my retirement party, again with a congratulatory gift: a magnificent art history book: $A$
History of African-American Artists: From 1792 to the Present by Romare Bearden and Harry Henderson. Included with the book was a note from Erich: "A footnote to Bearden. After discharge from the U.S. Army, I worked as a social investigator in the Harlem office of the NYC Department of Welfare. One of my co-workers was Romare Beardenabout 1947."

\section{Patricia E. Gallagher, AHIP:}

My friendship with Erich Meyerhoff began with dinner. A group of us had begun a monthly meeting of the "Bedpan Alley" librarians (an area of New York City from 14th Street to 34th Street, in which there were, at one point, five hospitals) for dinner. This social gathering quickly expanded to include librarians who lived in the area or who had worked in the area at one time. Mr. Meyerhoff became a regular; he attended virtually every dinner for years. As a result of these conversations, I was thrilled when he asked me to be the editor for the oral history in which he finally agreed to participate, but only because it was not about him, it was about the Medical Library Center of New York, a project that he dearly loved, and which sadly had ended.

His modesty was renowned among those who knew him. When I was asked to research the history of Chapter Council and scoured the minutes of the Medical Library Association annual meetings for information, his name popped up constantly. He was one of those who advocated actively for chapter participation in the governance of MLA. Yet, when I asked him for more information about the work, he told me, "I'm not important; you need to talk to Ursula Poland." He arranged for me to talk to Ms. Poland (a wealth of information), but at the end of the conversation, she said, "Why didn't you just asked Erich?" "I did; he said he wasn't important." She sighed. "That's him," she said. "He was very important." "I know," I said. "He still is." And he always will be.

\section{Ellen Poisson:}

I have so many memories of Erich from my time working as a reference librarian at the Cornell Medical Library, approximately 1980-1985. I first met him when I took his course on medical reference sources at Columbia. On the first day of class, he said he was glad we were all taking his course, but there were no jobs. The following week, he announced that two of his reference librarians were expecting and was anyone interested in a temporary job? I was!

The next year, the MLA annual meeting was in San Antonio, and Erich took most or all of the librarians at CUMC to the meeting. And I remember that he took us all out for Tex-Mex. He was always extraordinarily generous 
in sharing his knowledge and in his support of those young in the profession.

He was also undeterred in his pursuit of answers to reference questions. I remember watching from the reference desk one time when he really got going with a research question, and the medical student tagged along behind him as he went from one source to the next.

At Cornell, he set a high standard for service and also maintained an excellent, collegial relationship with the doctors and professors. I am so very grateful for all his help and encouragement in advancing my career. And for his sense of humor!

\section{Susan Crawford, AHIP, FMLA:}

I first met Erich at MLA-Montreal [1981] when I just became head of the [American Medical Association] AMA Archives and Library. I visited him in a tour of New York libraries with the likes of Gertrude Annan, Jacque Felter, and Estelle Brodman, and I'll never forget: he said, "Libraries are alike; let's just go visit the tapestries at the Cloisters!" We remained in touch all his life. Au revoir, Erich.

\section{Ellen Gay Detlefsen:}

I first met Erich in 1970 when he, together with Eric Moon (then the editor of Library Journal) organized a special meeting of the Archons of Colophon, a society of leading library administrators (all men!) in New York City. The meeting was to address the issues of emerging social concerns in librarianship at a time when the country was in the throes of the many movements for change; Erich asked me to speak on women's issues, together with E.J. Josey on black civil rights and Israel Fishman on the emerging gay rights movement. We three did, and Erich took great delight in telling me that this was the first time that a woman had ever spoken (or even attended!) an Archons meeting. He was our champion for social justice!

Retirement was always a sketchy concept for Erich; if anything, he began to work even harder with the archival collections at the NYU medical library and became active in the Archivists' Roundtable of New York City. Archives became a new career, which he pursued well past any reasonable idea of "retirement." But his interest in mentoring and supporting his library and archives colleagues, and his devotion to the standards of his chosen professions never flagged.

Erich Meyerhoff was a unique and wonderful man. We are all the better for having known and worked with him.

\section{AUTHOR'S AFFILIATION}

Stephen J. Greenberg, MSLS, PhD, greenbes@ mail.nih.gov, History of Medicine Division, National Library of Medicine, Bethesda, MD 20894 